\title{
4-Nerolidylcatechol induces autophagy in human glioblastoma cells
}

\author{
Renato Ramos Massaro ${ }^{1}$, Carla Abdo Brohem ${ }^{1}$, Rebeca Leite de Almeida ${ }^{1}$, Diogo Pineda Rivelli ${ }^{1}$, \\ Juliano Andreoli Miyake ${ }^{2}$, Alison Colquhoun², Silvia Berlanga de Moraes Barros ${ }^{1}$, Silvya Stuchi \\ Maria-Engler ${ }^{1 *}$
}

\begin{abstract}
${ }^{1}$ Department of Clinical Chemistry and Toxicological Analysis, School of Pharmaceutical Sciences, University of São Paulo, Brazil, ${ }^{2}$ Department of Cell Biology and Development, Institute of Biomedical Sciences, University of São Paulo, Brazil.
\end{abstract}

\begin{abstract}
Gliomas account for the majority of primary malignant brain tumors and present invasive behavior into adjacent healthy tissue. While 4-NC had previously shown to induce apoptotic cell death in a melanoma model, for the glioma model described in this paper 4-NC is cytotoxic for the cells with the induction of the autophagic pathway. Trypan blue exclusion assay showed that 4-NC was cytotoxic in a dose-dependent manner for $\mathrm{A} 172$ and $\mathrm{T} 98 \mathrm{G}$ cell lines. $\mathrm{IC}_{10}$ and $\mathrm{IC}_{50}$ values were at $32 \mu \mathrm{M}$ and $41 \mu \mathrm{M}$ for $\mathrm{A} 172$ and T98G respectively. Inhibition of cell proliferation was observed by total cell counts and by cell cycle analysis by flow cytometry, with cell cycle arrest of A172 and T98G cell lines respectively in the G1/G0 and S phases of the cell cycle. 4-NC induced up-regulation of autophagic pathways, as shown by immunoblotting for LC3-I/II, Real-Time PCR for ATG-7 and Beclin-1 genes, and by fluorescence microscopy observation of autophagic vacuoles in cells transfected with GFP-LC3 and electron microscopy. Glioma cells concomitantly treated with 4-NC and 3-MA, an inhibitor of the autophagic process, are more sensible to cell death, suggesting that autophagy protects the cells from the action of 4-NC.
\end{abstract}

Keywords: 4-Nerolidylcatechol. Glioblastoma. Cytotoxicity. Autophagy.

\section{INTRODUCTION}

Glioblastoma is the most common malignant brain tumor in adults. Despite advances in surgical techniques, radiation therapy and chemotherapy, the prognosis remains poor and the death of most patients occurs within 1-2 years after diagnosis (Jian et al., 2014). Primary brain glioblastomas are characterized by rapid diffusely infiltrative growth associated with high therapeutic resistance (Sana et al., 2011). Therefore, the understanding of molecular mechanisms and signaling pathways involved in cell death and cell proliferation of these tumors are highly desirable.

The Brazillian flora is constantly explored by many researches looking for new therapeutic agents and most of them still need to be characterized by biological and pharmacological studies. The Pothomorphe umbellata (L.) Miq. (Piperaceae) root extract, native to Atlantic Forrest has previously been shown to have antioxidant activity

\footnotetext{
*Correspondence: S. S. Maria-Engler. Clinical Chemistry and Toxicology Department, School of Pharmaceutical Sciences, University of São Paulo. Avenida Lineu Prestes, 580 Bloco 17, 05508-900 - São Paulo, SP - Brazil. Phone: 5511 30913631.E-mail: silvya@usp.br
}

when tested in a UVB-induced photoaging model, and the antioxidant activity, which has been shown to be more potent than $\alpha$-tocopherol, has been attributed to its main compound, 4-nerolidylcatechol (4-NC) (Ropke et al., 2006). Our previous study has tested this compound in an in vitro melanoma model, and has demonstrated its ability to induce apoptosis and inhibit MMP-2 activity and cell invasion (Brohem et al., 2012).

Many anticancer agents induce apoptosis and the inhibition of apoptotic process can reduce the sensitivity of tumor cells to anticancer treatments. Thus, drugs that induce this process remain the most used chemotherapeutic agents in medical oncology (Su, Mei, Sinha, 2013). However, many cancer cells, including glioma, are not responsive to the induction of apoptosis and they become resistant to a great number of chemotherapeutic agents (Lefranc, Facchini, Kiss, 2007). These characteristics indicate that the induction of apoptosis is not the only answer to cancer therapy, and that non-apoptotic mechanisms can be responsible for treatment-induced tumor cell death (Su, Mei, Sinha, 2013).

Autophagy is a genetically programmed highly regulated self-eating process via lysosomes induced as an 
adaptative response to unfavorable conditions ( $\mathrm{Su}, \mathrm{Mei}$, Sinha, 2013; Rebecca et al., 2014; Maycotte, Thorburn, 2011). In some cases, alternative cell death pathways other than apoptosis can lead to tumor cell death. In the past decade investigators have begun to focus on non-apoptotic types of cell death in cancer, including autophagic cell death, which is characterized by a greater extent of autophagic vacuole formation than is observed during physiological autophagy (Maycotte, Thorburn, 2011).

There can also be crosstalk between apoptotic and autophagic pathways, for example, inhibition of apoptosis can increase autophagy, and inhibition of autophagy may increase apoptosis (Su, Mei, Sinha, 2013). The alkylating agent temozolomide, the main chemotherapeutic agent used for glioblastoma treatment (Hottinger, Stupp, Homicsko, 2014) can induce malignant glioma cell death through the autophagic pathway (Kanzawa et al., 2004). Conversely, in some cases, autophagy protects cancer cells from drug-induced apoptosis, and agents that block autophagy might strengthen the antitumor efficacy of cytotoxic agents (Su, Mei, Sinha, 2013; Rebecca et al., 2014; Maycotte, Thorburn, 2011). Su, Mei and Sinha (2013) discuss that autophagy induction by cytotoxic events has a dual role, and it is often-unclear whether it acts as a cell death mechanism or an effort for cell maintenance.

In this work, based on our previous results where 4-NC overcame chemoresistance in melanoma model, we evaluate the cytotoxicity of 4-NC extracted from $P$. umbellate in two invasive glioblastoma cell lines, A172 and T98G focusing on the role of autophagy. Cell death was assayed by membrane integrity and DNA fragmentation was determined by flow cytometry along with cell cycle distribution, showing that 4-NC was toxic in a dose dependent manner with inhibition of proliferation at lower doses. The effect of 4-NC on the induction of the autophagyrelated genes and proteins were investigated by quantitative real time PCR and immunoblotting. The induction of autophagy was also observed by the formation of vacuoles in the cell lines with GFP-LC3 and by electron microscopy.

\section{MATERIAL AND METHODS}

\section{4-Nerolidylcatechol isolation}

4-NC was isolated from the crude P. umbellata hidroethanolic root extract. Briefly, roots of $P$. umbellata were dried, milled and exhaustively extracted by percolation with ethanol:water $(1: 1)$. The freeze-dried crude extract was resuspended in ethanol and submitted to liquid:liquid extraction with hexane. The hexane layer volume was reduced under nitrogen and further submitted to a semi- preparative High Performance Liquid Chromatography system for 4-NC isolation. A Shimadzu SCL 10A VP HPLC system (Kyoto, Japan) equipped with a UV/VIS detector (SPD 10A VP-diode array), Class VP software and a Phenomenex Luna C18 column (Torrance, CA) (10 $\mu \mathrm{m}, 250 \times 10 \mathrm{~mm}$ ), using 9:1 MeOH (Merck, Darmstad, Germany): $\mathrm{H}_{2} \mathrm{O}$ as mobile phase, provided the pure 4-NC. The structure of 4-NC was deduced by spectroscopic analysis and confirmed by comparison of its spectral features with published values (Ropke et al., 2006).

\section{Cell culture}

The human malignant glioblastoma cell lines A172 and T98G used in this work were obtained from the American Type Culture Collection (ATCC, Rockville, MD, USA) and kindly provided by Professor Mari Cleide Sogayar, Institute of Chemistry, University of São Paulo. 293FT cells were kindly obtained from Nathalie Cella, Institute of Biomedical Science, University of São Paulo, and used as packaging cells as described below. All cells were grown in Dulbecco's modified Eagle's medium (DMEM) supplemented with $10 \%$ fetal bovine serum (FBS), $50 \mathrm{U} / \mathrm{mL}$ penicillin and $50 \mu \mathrm{g} / \mathrm{mL}$ streptomycin, and maintained at $37{ }^{\circ} \mathrm{C}$ under $5 \% \mathrm{CO}_{2}$ atmosphere. The pure 4-NC was dissolved in ethanol to a concentration of $10 \mathrm{mM}$ and stored at $-20^{\circ} \mathrm{C}$. The concentration of ethanol in culture never exceeded $0.2 \%$, and exhibited $100 \%$ cell viability when compared to untreated cultures.

\section{Measurement of cell viability}

For the measurement of cell viability, $4 \times 10^{4}$ cells from each cell line were seeded on 24-well plates and after a $24 \mathrm{~h}$ attachment period cultures were treated with $4-\mathrm{NC}$ at concentrations of $25,32,41$ or $48 \mu \mathrm{M}$. Following a 24-48 $\mathrm{h}$ incubation period, cell viability was assessed by counting live versus dead cells on a hemocytometer using the Trypan Blue $(0.4 \%$ in phosphate-buffer saline, PBS) exclusion staining. The assay was done in quadruplicate. Autophagy inhibition experiments, were performed using cells treated with 3-Methyladenine (3-MA, Fluka Chemic AG, Buchs, Switzerland) at a concentration of $2 \mathrm{mM}$ with or without 4-NC at a concentration of $32 \mu \mathrm{M}$.

\section{Analysis of membrane integrity}

Cells $\left(2 \times 10^{5}\right)$ were plated on a 6 -well plate and following $24 \mathrm{~h}$ treatment with 4-NC $(10,13$ or $15 \mu \mathrm{g} /$ $\mathrm{mL}$ ), cells were harvested and centrifuged at $1000 \mathrm{rpm}$ for $5 \mathrm{~min}$ at $4^{\circ} \mathrm{C}$. Plasma membrane integrity was assessed 
as described by Brohem et al. (2012). Briefly, following the $24 \mathrm{~h}$ treatment, $50 \mu \mathrm{L}$ of a propidium iodide (PI; Sigma Chemical, St. Louis, MO, USA) labeling solution $(20 \mu \mathrm{g} / \mathrm{mL}$ in PBS) was added to $0.5 \mathrm{~mL}$ of DMEM containing harvested cells. After 5 min incubation at room temperature, cells were evaluated in a FACScalibur flow cytometer (Becton Dickinson, California, USA) using the Cell Quest software. Fluorescence was measured using the FL2 channel (orange-red fluorescence 585/42 nm filter). Ten thousand events were analyzed per experiment and the assay was done in triplicate.

\section{DNA fragmentation analyses}

Cells were obtained as described above. The pellet was resuspended in $0.3 \mathrm{~mL}$ of lysis buffer $(0.1 \%$ sodium citrate and $0.1 \%$ Triton X-100) containing $0.02 \mathrm{mg} / \mathrm{mL}$ PI. After $30 \mathrm{~min}$ incubation at room temperature, the fluorescence was measured by flow cytometry. DNA fragmentation was observed by the presence of particles exhibiting low fluorescence, indicative of cleaved DNA. The cells were evaluated in a FACScalibur flow cytometer as described above.

\section{Real time PCR}

Total RNA from cells was isolated using TRIzol Reagent (Invitrogen, Carlsbad, CA, USA) for mRNA analysis. One microgram of total RNA was used to assess relative levels of mRNA, using SYBR ${ }^{\circledR}$ Green quantitative real-time PCR (Applied Biosystems, Foster City, CA, USA) and normalized to tubulin mRNA. Relative expression was calculated using the comparative CT method (Delta-Delta-Ct (DDCt)) (Livak, Schmittgen, 2011). The following primers used for quantitative realtime PCR were designed in Primer3 Software: h-Tubulin F: 5'TCA ACA CCT TCT TCA GTG AAA CG3'; h-Tubulin R: 5'AGT GCC AGT GCG AAC TTC ATC3'. h-ATG-7 F: 5'ATC TCA GAT GGT CTC ATC ATC GCT CA3'; h-ATG-7 R: 5'GAA GAC TTG ACT GGT CTT ACA TTG CTG CAT3'. h-Beclin-1 F: 5'TTT CAA GAT CCT GGA CCG TGT CAC CAT3'; h-Beclin-1 R: 5'TTC GCC TGG GCT GTG GTA AGT AAT GGA3'. All quantitative real-time PCR reactions were performed in triplicates and the data are presented as mean +/- SED (Standard Error Deviation).

\section{Western Blotting}

Cells were lysed by a standard procedure using Radioimmunoprecipitation assay (RIPA) plus buffer containing protease and phosphatase inhibitor cocktail (Sigma Aldrich, saint Louis, MO, USA). Protein concentrations of total cell lysates were measured by the Bradford method and $50 \mu \mathrm{g}$ per lane of total cell lysates was resolved on a 4-20\% gradient (sodium dodecyl sulfate) SDS-polyacrylamide electrophoresis gels. Proteins were transferred to nitrocellulose membrane (Applied Biosystems, Foster City, CA, USA) followed by immunoblot detection and visualization with ECL western blotting detection reagents (GE Healthcare Life Sciences, Munich, Germany). Immunoblotting was performed with the mouse anti-LC3 (1:500; Cell Signaling, Danvers, MA, USA) and mouse anti-tubulin (1:5000; Sigma-Aldrich, St Louis, MO, USA) primary antibodies. Secondary antibody used was goat anti-mouse antibody (1:5000; Jackson ImmunoResearch Labs, West Grove, PA, USA).

\section{Lentiviral transfection with pLV-GFP-LC3}

Recently, green fluorescent protein (GFP)-tagged LC3 expressing cells have been used to demonstrate induction of autophagy (Tormo et al., 2009). GFP-LC3 expressing cells present a diffuse distribution under control conditions, and punctuate GFP-LC3 labeling upon formation of the autophagosome. Viral packaging cell line 293FT (Invitrogen, Carlsbad, CA, USA) was transfected with viral packaging plasmids and pLV-GFP-LC3 by $\mathrm{Ca}^{2+}$-phosphate with the addition of chloroquine (SigmaAldrich, St Louis, MO, USA) to the cell media at final concentration of $25 \mu \mathrm{M}$. These plasmids were very kindly provided by Dr. María S. Soengas (CNIO-Spain) (Tormo et al., 2009). Following an $8 \mathrm{~h}$ transfection, media was replaced by the addition of fresh DMEM containing $10 \%$ FBS to remove chloroquine. The supernatant of 293FT virally-transfected cells was collected $48 \mathrm{~h}$ later, mixed with polybreen (Sigma-Aldrich, St Louis, MO, USA) to a final concentration of $4 \mu \mathrm{g} / \mathrm{mL}$, and filtered through 0.45 $\mu \mathrm{m}$ filters. This supernatant was directly added to cell lines A172 and T98G. This procedure was repeated $12 \mathrm{~h}$ following the first infection. Selection with puromycin was initiated $24 \mathrm{~h}$ after changing media. Following selection, cells were plated and treated with 4-NC. Control cells were infected with empty pLV plasmid.

\section{Electron Microscopy}

Cells from A172 and T98G cell lines were seeded $\left(1 \times 10^{6}\right)$ in $100 \mathrm{~mm}$ dishes and allowed to adhere overnight, after which they were treated with 4-NC $(0$, 10 and $13 \mu \mathrm{g} / \mathrm{mL}$ ). Cells were collected, washed twice in PBS, pelleted and fixed for $4 \mathrm{~h}$ in $4 \%$ formaldehyde, 
$2 \%$ glutaraldehyde in $0.1 \mathrm{M}$ potassium phosphate buffer $(\mathrm{P}(\mathrm{K}))$. Cells were washed in $\mathrm{P}(\mathrm{K})$ buffer and post-fixed in $2 \%$ osmium tetroxide (Electron Microscopy Sciences, Fort Washington, PA, USA) in P(K) buffer for $1 \mathrm{~h}$. They were then stained in 5\% uranyl acetate (Electron Microscopy Sciences, Fort Washington, PA, USA) in $10.56 \%$ sucrose solution for $2 \mathrm{~h}$. Cells were gradually dehydrated in ethanol solutions with increasing ethanol concentrations, washed twice for $10 \mathrm{~min}$ in propylene oxide (Electron Microscopy Sciences, Fort Washington, PA, USA), and then incubated for $1 \mathrm{~h}$ in a 1:1 solution of propylene oxide:resin. Final embedding was done in resin Embed-812 (Electron Microscopy Sciences, Fort Washington, PA, USA). The resin was changed twice after $2.5 \mathrm{~h}$ incubation and once more after overnight incubation. Following $24 \mathrm{~h}$ incubation at $65^{\circ} \mathrm{C}$, semi-thin sections of the pellets were obtained on a Sorvall MT2B microtome (DuPont Instruments, Wilmington, DE, USA) to evaluate the quality of cells. Ultrathin sections were obtained on a Leica ultracut-R ultramicrotome (Leica, Vienna, Austria) and examined on a JEOL (JEM Jeol Model 100 CX II, Tokyo, Japan) electron microscope.

\section{Statistical Analysis}

Data were expressed as the mean \pm SD (standard deviation). Statistical analysis was carried out with the Graph Pad InStat software (version 3.01 for Windows 95, Graph Pad Software, San Diego, CA). One-way ANOVA with a multiple comparison test (Tukey test) was used for data analysis. For the comparison of cell death between cells treated with 4-NC alone and 4-NC in the presence of 3-MA a paired $t$ test was performed. Statistical significance was defined by a "p" value under 0.05 .

\section{RESULTS}

\section{4-Nerolydilcatechol is cytotoxic for glioblastoma cell lines A172 and T98G}

Treatment of cells in the presence of 4-NC at increasing concentrations demonstrated that $4-\mathrm{NC}$ is cytotoxic for the cell lines analyzed as determined by Trypan Blue exclusion assay and flow cytometric analysis of membrane integrity. Cytotoxicity induced by 4-NC starts to be evident at concentrations higher than $32 \mu \mathrm{M}$ (Figure 1A). At a concentration of $41 \mu \mathrm{M}, 4-\mathrm{NC}$ kills approximately $50 \%$ of the cells in culture, and less than $20 \%$ of cells remain viable at a concentration of $48 \mu \mathrm{M}$ in both cell lines at $24 \mathrm{~h}$ as shown by Trypan Blue exclusion assay (Figure 1B). Flow cytometric analysis of membrane integrity (Figure 1C) shows similar results when compared to Trypan Blue assays.

After incubation with the compound for 24 hours, cells displayed morphological changes even at concentrations that are not typically cytotoxic, such as cell elongation and loss of cell-cell contact, indicating that 4-NC has effects on cell metabolism prior to any cytotoxic effects (Figure 1A). In higher doses we are able to visualize vacuoles in the cell cytoplasm.

Flow cytometric analysis revealed a dose-dependent cytotoxic effect of 4-NC on glioma cells, as determined by increasing DNA fragmentation when cells were treated with the higher concentrations of 4-NC (Figure 1D). Labeling of cellular nucleic acids with PI following membrane rupture caused by 4-NC treatment (Figure 1C) is observed, indicating cell death is caused by this compound, with disruption of cell membrane. It is important to add that, despite it was not possible to work with primary normal human glial cells, in a previous work it was demonstrated that primary fibroblasts are less sensitive to the effects of 4NC than tumor cells (Brohem et al., 2012).

Pictures of the two glioma cell lines after incubation with 4-NC for $24 \mathrm{~h}$ (A) showing the effect of this compound on the morphology of the cells. Bar $=600$ $\mu \mathrm{m}$. Curves (B) show a response in a dose dependent manner after incubation with 4-NC. Membrane integrity (C) was assessed by flow cytometry. Percentage of DNA fragmentation (D) in both glioma cell lines after treatment with 4-NC for $24 \mathrm{~h}$. (E) Total cell number was counted to assess the proliferation of the cells during the time of incubation with 4-NC in the concentrations indicated. For the cell cycle assay (F) cells were treated with 4-NC at the concentration of $32 \mu \mathrm{M}$ for $24 \mathrm{~h}$. Each bar represents the mean \pm SEM of three separate experiments. $* \mathrm{P}<0,05$; ** $\mathrm{P}<0,01 ; * * * \mathrm{P}<0,001$ compared to the control (untreated) cells.

\section{4-Nerolydilcatechol induces impairment of cell proliferation}

The cell cycle can be arrested by the regulation of multiple checkpoints as will be discussed further. Cellular proliferation was therefore assessed by total cell counts after $24 \mathrm{~h}$ of treatment with 4-NC at different doses. As shown in Figure 1E, alterations in total cell counts were already observed at $25 \mu \mathrm{M}$ of $4-\mathrm{NC}$ in cell line T98G, with even more significant decreases in cell counts at 32 $\mu \mathrm{M}$ of the compound indicating a dose dependent effect on cellular proliferation.

Flow cytometric analysis of the DNA content of cells following membrane lysis indicated an increase in 

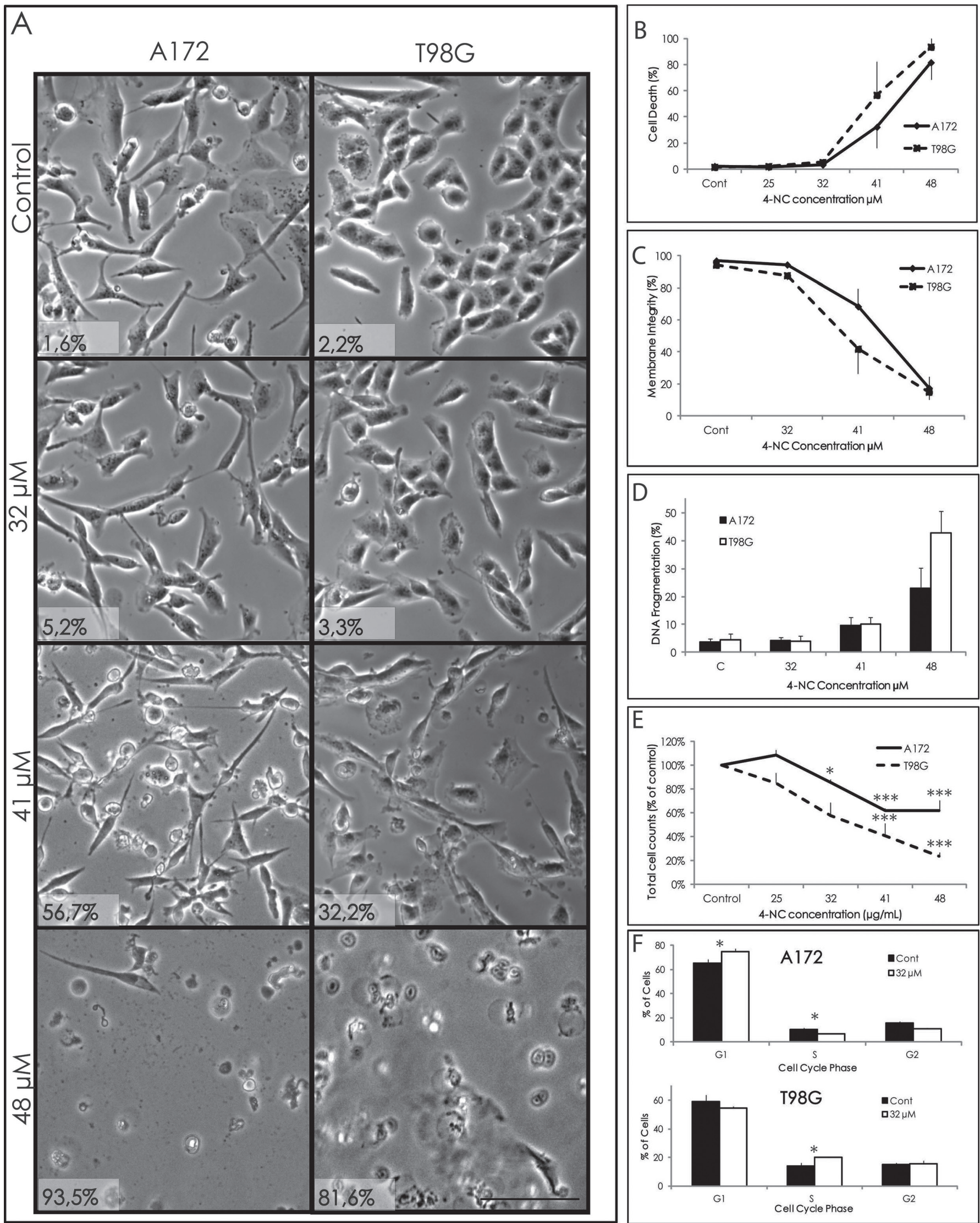

FIGURE 1 - Effects of 4-NC in cytotoxicity, DNA fragmentation and proliferation. 
the population of cells in G1 phase and S phase of the cell cycle, for A172 and T98G cells, respectively (Figure 1F). This data was obtained by treating the cells with 32 $\mu \mathrm{M} 4-\mathrm{NC}$, a concentration that does not induce cell death following $24 \mathrm{~h}$ of treatment $\left(\mathrm{IC}_{10}\right)$, revealing the potential of 4-NC on regulating cell cycle promoting its arrest even at non-cytotoxic doses.

\section{4-Nerolydilcatechol induces autophagosome formation in glioma cell lines}

An extensively used method as a marker for autophagy is the conversion of the cytoplasmatic form of LC3 (LC3-I, 16kDa) to the pre-autophagosomal and autophagosomal membrane-bound form of LC3 (LC3II, $14 \mathrm{kDa}$ ) by western blot. Figure $2 \mathrm{~A}$ demonstrates increasing intensities of the LC3-II band in a dose dependent manner for both cell lines when treated with 4-NC for $24 \mathrm{~h}$. This increase is not observed at early time points (6h) following 4-NC treatment. Upon quantification of LC3-I and LC3-II band intensities following 4-NC treatment, the difference is significant for the concentration of $41 \mu \mathrm{M}$ of $4-\mathrm{NC}$ (Figure 2B).

Immunoblotting for the autophagy related protein LC3. Cells were treated with $4-\mathrm{NC}$ for $6 \mathrm{~h}$ and $24 \mathrm{~h}$ at the concentrations indicated. Quantification of the immunoblotting (B). Each bar represents the mean \pm SEM of three separate experiments. ${ }^{*} \mathrm{P}<0,05$ compared to the control (untreated) cells. Photos under fluorescent microscopy (C) showing LC3-GFP labeled autophagossomes on cells A172 and T98G cells. Cells treated with $4-\mathrm{NC}$ at the concentration of $41 \mu \mathrm{M}$ have higher amounts of GFP-LC3 dots, showing induction of autophagy in these cells. Bar $=50 \mu \mathrm{m}$.

Cells were infected with lentiviral constructs expressing GFP labeled LC3 to verify the induction of autophagy. As shown in Figure 2C, punctuate fluorescence as cytosolic dots representing the formation of autophagosomes were observed in both cell lines when exposed to 4-NC treatment at the concentration of $41 \mu \mathrm{M}$ for $24 \mathrm{~h}$. These labeled autophagosome vacuoles indicate autophagy was induced by the compound in these cells. Cells treated with the positive controls Krebs Ringer Medium (KR) for $4 \mathrm{~h}$ and Rapamycin (Rapa) at $100 \mu \mathrm{M}$ for $24 \mathrm{~h}$ show that the increased punctuation is due to autophagy induction (Data not shown). Electron microscopy was performed in cells under the same conditions, and the increase in vacuole formation was also observed. Cells treated with Rapamycin at $100 \mu \mathrm{M}$ for $24 \mathrm{~h}$ show similar vacuolar structures, with double and multiple membrane (Figure 3A). Details of the cytosol of the treated cells show double or multiple membrane vesicles (Figure $3 \mathrm{~A}$ pictures at the bottom) indicating the occurrence of the autophagy. Krebs Ringer Medium is used to induce starvation conditions by depriving cells from amino acids, thus inducing autophagy. Rapamycin

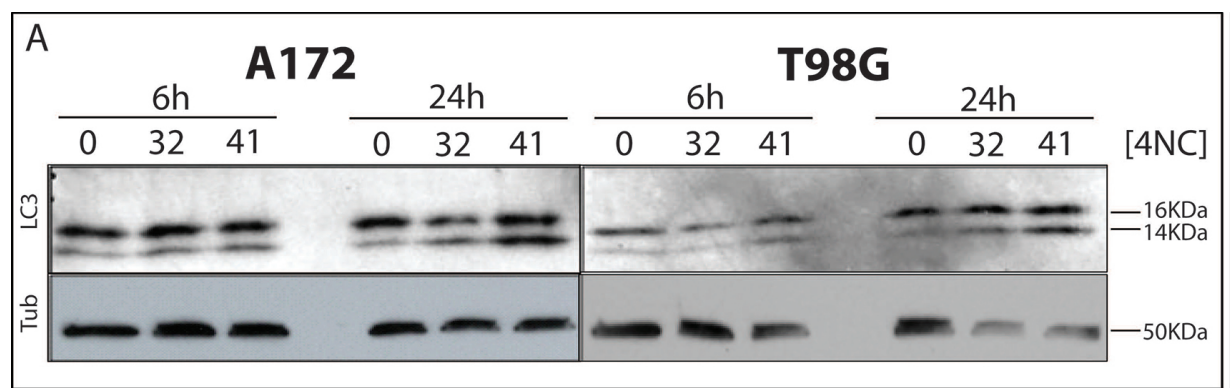

$\begin{array}{ll}\mathrm{A} & \mathbf{1 7 2}\end{array}$

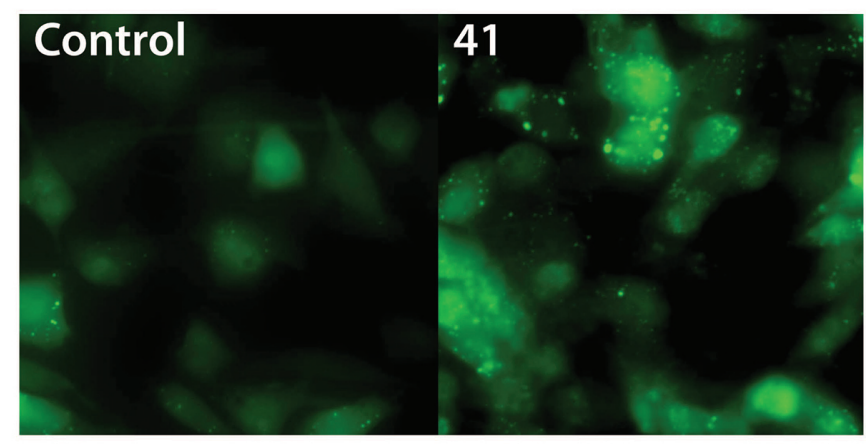

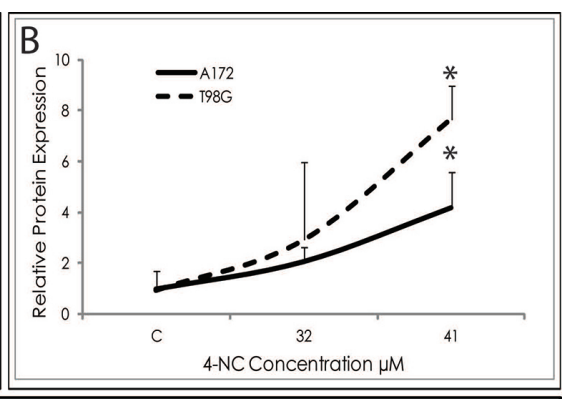

T98G

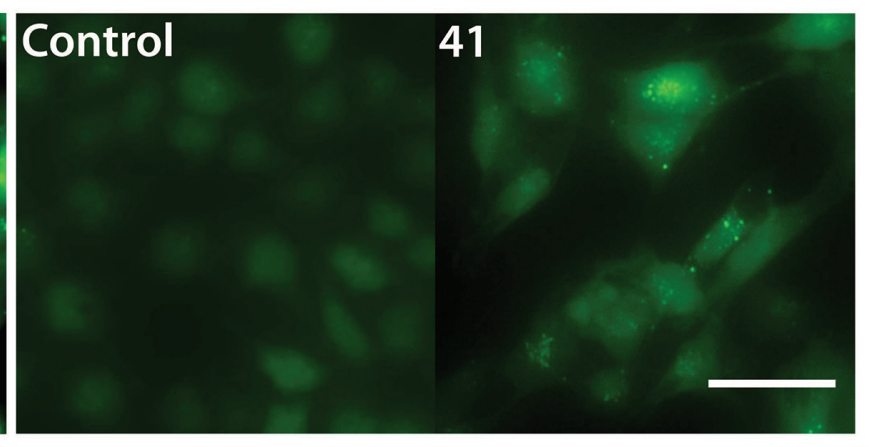

FIGURE 2 - 4-NC induction of autophagy by the increase of LC3-II. 
is also used as a positive control for autophagy by the inhibition of mTOR (mammalian target of rapamycin) pathway (Klionsky et al., 2012).

Electron microscopy (A) of control cells and cells treated with $41 \mu \mathrm{M}$ of 4-NC show that under 4-NC treatment at this concentration there is an increase in the formation of vacuoles with double membranes (lower pictures for details). (B) The expression of genes related and essential to autophagy ATG-7 and Beclin-1 was upregulated. (C) Cell viability was assessed by Trypan Blue exclusion assay in the presence of autophagy inhibitor 3-MA. When the two columns (4NC x 4NC+3MA) are compared using paired $t$ test a significant difference is observed $(\mathrm{p}=0,0045$ for both cell lines). Each bar represents the mean \pm SEM of three separate experiments. ${ }^{*} \mathrm{P}<0,05$; ** $\mathrm{P}<0,01 ; * * * \mathrm{P}<0,001$ compared to the control (untreated) cells. $(*) \mathrm{P}=0,0045$ in paired t test. Electron microscopy $\mathrm{Bar}=3.3 \mu \mathrm{m}$ and $1.25 \mu \mathrm{m}$ for the detail pictures.
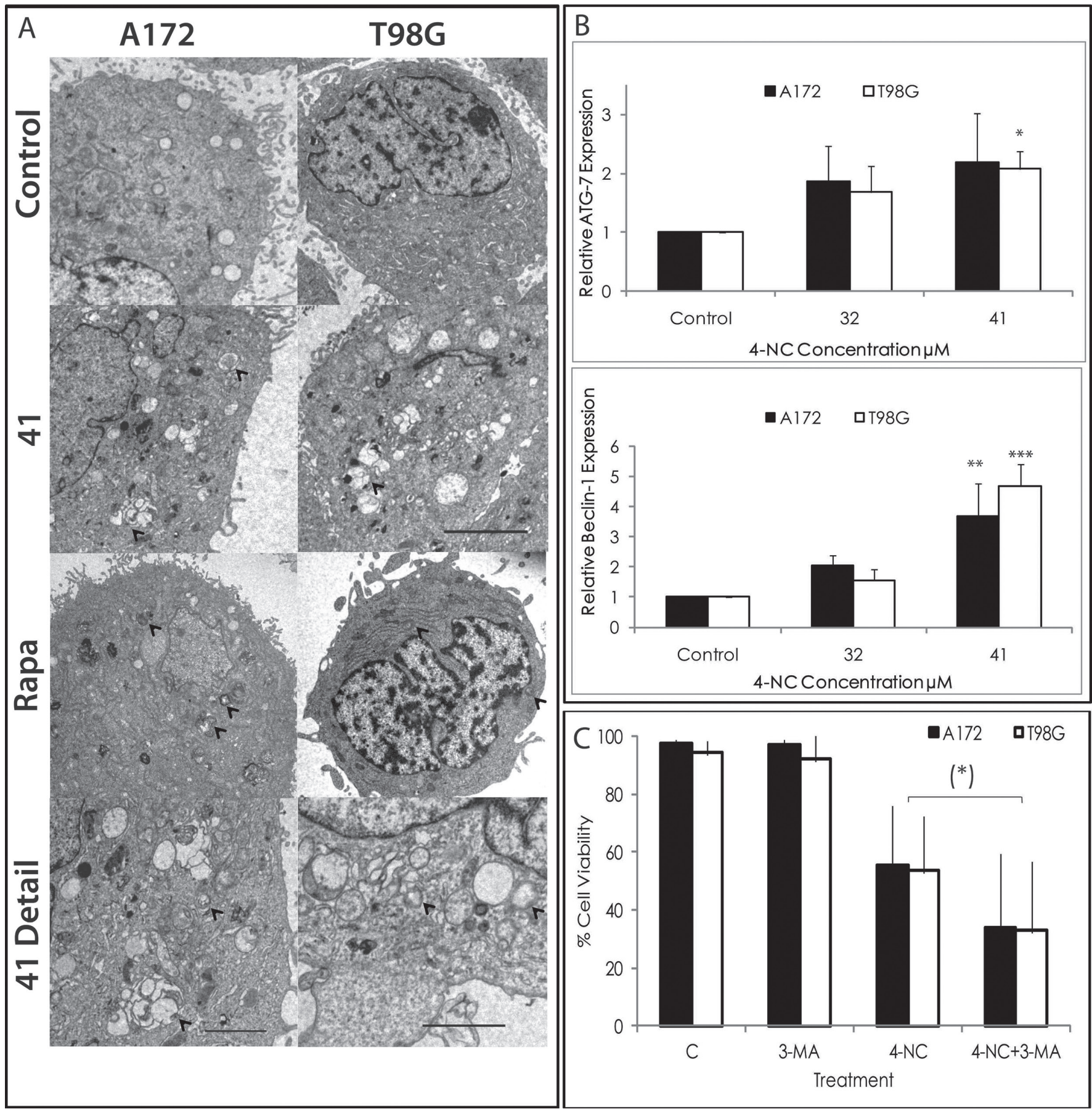

FIGURE 3 - Effect of 4-NC on autophagy induction. 
It has been demonstrated that the expression of the genes Beclin-1 and ATG-7 are essential for the autophagic process to occur. Beclin-1 could play a role in recruiting proteins from the cytosol for autophagic degradation or in supplying autophagic pathway with membrane components (Li, Qin, Liang, 2009). ATG-7 is also required for autophagosomes formation, and the inhibition of its expression reverted the autophagic induced cell death by $\mathrm{H}_{2} \mathrm{O}_{2}$ (Chen et al., 2008). Furthermore, RNA interference targeting the expression of these mRNAs led to impaired induction of autophagy (Chen et al., 2008). We therefore quantified expression levels of genes involved in the formation of autophagosomes by quantitative Real Time PCR.

The expression levels of both Beclin-1 and ATG-7 genes were upregulated by $4-\mathrm{NC}$ in a dose dependent manner as shown in Figure 3B. ATG-7 (upper graphic) showed statistically significant increased expression only for the cell line T98G at the concentration of $41 \mu \mathrm{M}$, although the graphic shows a tendency of increase in the expression of the two cell lines in both concentrations of treatment. Beclin-1 (lower graphic) showed a statistically significant increase in the expression of the gene in both cell lines at the concentration of $41 \mu \mathrm{M}$.

The autophagy pathway can promote cell adaptation and survival but under some conditions it can also lead to cell death (Su, Mei, Sinha, 2013). To further elucidate the role of autophagy in the glioma cells, we inhibited this process by addition of 3-methyladenine (3-MA), a known inhibitor of the autophagic process.

If autophagy was leading to cell death an inhibition of this process would be observed. As shown in figure 3C, treatment with 3-MA in the presence of 4-NC for $24 \mathrm{~h}$ led to an increase in cell death. This indicates that in this model, autophagy is acting as a protective response of the cells from the cytotoxic effects of 4-NC, since we observe an increase in cell death when it is inhibited. The autophagy inhibitor 3-MA alone did not affect cell viability.

\section{DISCUSSION}

One of the most important issues of glioblastoma that lead to poor patient prognosis is chemoresistance to conventional treatment. Our work provides new data concerning the resistance of A172 and T98G glioma cell lines to drugs, showing that the compound 4-NC is able to impair cell proliferation via promotion of cell cycle arrest. At higher doses, 4-NC is able to lead these chemoresistant cells to death with the induction of autophagy as an effort from these cells to overcome the stress caused by the compound.

\section{Cell cycle}

The cell cycle is controlled at many checkpoints by cyclin dependent kinases (cdks)/cyclin complexes and upstream proteins that inhibit these complexes, such as p21 and p27 (Sherr, Roberts, 2004). We demonstrate here that $4-\mathrm{NC}$ is able to affect cell proliferation negatively. The arrest in the cell cycle occurs in different phases for the two different cell lines assayed. For A172 there is an increased population of cells in the G1 phase of cell cycle, while for T98G the arrest is in the S phase. In terms of total cell counts this inhibition was approximately $20 \%$ and $40 \%$ for A172 and T98G cell lines respectively, in a sub-toxic concentration ( $32 \mathrm{uM}$ ) of the compound, which have shown a significant decrease in total cell counts.

Since there are a multitude of different regulators controlling the cell cycle at various checkpoints, further investigation is necessary to elucidate the exact mechanism of action of 4-NC on cell cycle regulators.

\section{Cytotoxicity and cell death}

The cytotoxicity of 4-NC can be observed in both cell lines used in this work, ultimately resulting in cell death. There are many ways by which cell death can be induced and many cancer treatments aimed at inducing programmed cell death type I, better known as apoptosis.

The malignant transformation of a normal cell into a tumor cell requires a number of alterations. In most gliomas (as well as in many other tumors) these transformations lead to the capacity to evade apoptosis. Evasion of apoptosis is known to result in resistance to anti-cancer therapies (Lefranc, Facchini, Kiss, 2007).

In the present study, however, the PI staining in the 4-NC treated cells indicates that the membrane is permeable, suggesting that apoptosis is not the key driver of cell death following 4-NC exposure. As reviewed by de Burin and Medema (de Bruin, Medema, 2008), alternative types of cell death may compensate for the resistance to apoptosis often seen in tumor cells.

Cellular stresses leading to cytotoxicity can induce recycling of the cytoplasm and damaged organelles. This adaptive recycling response of the cell in stress conditions is known as autophagy. In our present work, we identify for the first time that 4-NC is able to induced autophagy in two separate glioma tumor cell lines.

In cancer, autophagy is known to have a dual effect. On one side it can have cytoprotective role, removing damaged organelles and recycling proteins and other cellular components ( $\mathrm{Su}, \mathrm{Mei}$, Sinha, 2013, Rebecca et $a l ., 2014)$. On the other hand, if this process is pushed 
beyond a certain threshold it may result in cell death. There are cases where it may function in suppressing tumor development, inhibiting proliferation or even promote cell death, depending on the treatment (Su, Mei, Sinha, 2013). We evidenced that the cell death induced by $4 \mathrm{NC}$ leads to a stress that increases the autophagic pathway, and this autophagy acts as a protective response of the cells to the stress caused by the compound.

Temozolomide and rapamycin, which are known to induce autophagy, are used clinically to induce tumor regression. It becomes clear that, even if in this case, autophagy is not directly responsible for the cellular death (Kanzawa et al., 2004, Moretti et al., 2007). It is important to identify the induction of this process, because in association with other compounds, this may lead to a more effective treatment. For example, 3-MA, an autophagy inhibitor, enhances the effect of 5-FU induced cell death in colon cancer cells (Maycotte, Thorburn, 2011; Li et al., 2009). Our results suggest that 4-NC induces autophagy as a result of cellular stress. Autophagy would be a way to protect cells from the deleterious effects of this compound. This becomes more clear when, with the inhibition of autophagy by 3-MA, a tendency of increase in cell death is observed, showing that in this case, cell death is probably not directly due to autophagy.

Macroautophagy is a very complex process that can be induced by many pathways and involves several different proteins. To explain accurately the mechanism of induction of this cell response by 4-NC other experiments will have to be made.

\section{CONCLUSION}

All these data suggest that, as in our glioma model, where autophagy was induced by 4-NC and cell death was most likely non-apoptotic, a better understanding of these types of cell death will help us better evaluate their impact and importance on tumor development and treatment, especially in cases where cells are non-responsive to typical cancer treatments.

\section{ACKNOWLEDGEMENTS}

The authors gratefully acknowledge the funding support from FAPESP (Regular Project, Grants 06/509151, 06/60930-8 and 08-58817-4). Renato Ramos Massaro was a fellowship recipient of FAPESP Grants 06/58663-1 and CNPq, CAPES, and PRP-USP. We are also thankful for Dr. María Soengas for GFP-pLV-LC3 plasmid, Dr. Christian Colin for discussion and Dr. Monique Verhaegen for the valuable critical.

\section{REFERENCES}

Brohem CA, Massaro RR, Tiago M, Marinho CE, Jasiulionis MG, de Almeida RL, et al. Proteasome inhibition and ROS generation by 4-nerolidylcatechol induces melanoma cell death. Pigment Cell Melanoma Res. 2012;25(3):354-369.

Chen Y, McMillan-Ward E, Kong J, Israels SJ, Gibson SB. Oxidative stress induces autophagic cell death independent of apoptosis in transformed and cancer cells. Cell Death Differ. 2008;15(1):171-182.

de Bruin EC, Medema JP. Apoptosis and non-apoptotic deaths in cancer development and treatment response. Cancer Treat Rev. 2008;34(8):737-749.

Hottinger AF, Stupp R, Homicsko K. Standards of care and novel approaches in the management of glioblastoma multiforme. Chin J Cancer. 2014;33(1):32-39.

Jiang P, Mukthavavam R, Chao Y, Bharati IS, Fogal V, Pastorino $\mathrm{S}$, et al. Novel anti-glioblastoma agents and therapeutic combinations identified from a collection of FDA approved drugs. J Transl Med. 2014;12:1-13.

Kanzawa T, Germano IM, Komata T, Ito H, Kondo Y, Kondo S. Role of autophagy in temozolomide-induced cytotoxicity for malignant glioma cells. Cell Death Differ. 2004;11(4):448-457.

Klionsky DJ, Abdalla FC, Abeliovich H, Abraham RT, Acevedo-Arozena A, Adeli K, et al. Guidelines for the use and interpretation of assays for monitoring autophagy. Autophagy 2012;8(4):445-544.

Lefranc F, Facchini V, Kiss R. Proautophagic drugs: a novel means to combat apoptosis-resistant cancers, with a special emphasis on glioblastomas. Oncologist 2007;12(12):1395-403.

Li J, Hou N, Faried A, Tsutsumi S, Takeuchi T, Kuwano H. Inhibition of autophagy by 3-MA enhances the effect of 5-FUinduced apoptosis in colon cancer cells. Ann Surg Oncol. 2009;16(3):761-71.

Li J, Qin Z, Liang Z. The prosurvival role of autophagy in Resveratrol-induced cytotoxicity in human U251 glioma cells. BMC Cancer. 2009;9:215.

Livak KJ, Schmittgen TD. Analysis of relative gene expression data using real-time quantitative PCR and the 2(-Delta Delta C(T)) Method. Methods 2001;25(4):402-408. 
Maycotte P, Thorburn A. Autophagy and cancer therapy. Cancer Biol Ther. 2011;11(2):127-137.

Moretti L, Yang ES, Kim KW, Lu B. Autophagy signaling in cancer and its potential as novel target to improve anticancer therapy. Drug Resist Updat. 2007;10(4-5):135-43.

Rebecca VW, Massaro RR, Fedorenko IV, Sondak VK, Anderson AR, Kim E, et al. Inhibition of autophagy enhances the effects of the AKT inhibitor MK-2206 when combined with paclitaxel and carboplatin in BRAF wild-type melanoma. Pigment Cell Melanoma Res. 2014; 27(3):465-78.

Ropke CD, da Silva VV, Kera CZ, Miranda DV, de Almeida RL, Sawada TCH, et al. In vitro and in vivo inhibition of skin matrix metalloproteinases by Pothomorphe umbellata root extract. Photochem Photobiol. 2006;82(2):439-442.
Sana J, Hajduch M, Michalek J, Vyzula R, Slaby O. MicroRNAs and glioblastoma: roles in core signalling pathways and potential clinical implications. J Cell Mol Med. 2011;15(8):1636-1644.

Sherr CJ, Roberts JM. Living with or without cyclins and cyclindependent kinases. Genes Dev. 2004;18(22):2699-2711.

Su M, Mei Y, Sinha S. Role of the Crosstalk between autophagy and apoptosis in Cancer. J Oncol. 2013;2013:102735.

Tormo D, Checińska A, Alonso-Curbelo D, Pérez-Guijarro E, Cañón E, Riveiro-Falkenbach E, et al. Targeted activation of innate immunity for therapeutic induction of autophagy and apoptosis in melanoma cells. Cancer Cell. 2009;16(2):103-114.

Received for publication on $08^{\text {th }}$ November 2016 Accepted for publication on $07^{\text {th }}$ March 2017 